\title{
Sanja Marinov*
}

Faculty of Economics, Business and Tourism

University of Split, Croatia

smarinov@efst.hr

Višnja Pavičić Takač

Faculty of Humanities and Social Sciences

University of Osijek, Croatia

vpavicic@ffos.hr

\section{E.S.P.Today

NON-LANGUAGE MAJORS' STUDY ABROAD

\section{LANGUAGE LEARNING EXPERIENCES CAPTURED IN A NARRATIVE FRAME}

\section{Abstract}

Study abroad (SA) research involving Croatian students is still in its infancy, with hardly any documentation of systematic research. Thus, the present paper aims to explore the main themes permeating Croatian sojourners' SA experiences and their interrelatedness. The study utilises narrative frames (NFs), i.e. story templates that produce a coherent account of an individual's own experience (Barkhuizen, 2014), to elicit information on participants' perceptions of SA experience. The NF created for the purposes of this study aims at capturing language learning experiences in an SA context. The frames, completed by 33 Croatian students from non-language fields of study who participated in the Erasmus student exchange programme in various European destinations, were analysed using the grounded theory (GT) approach. All stages of the procedure are meticulously detailed in the study. The all-encompassing idea resulting from the analysis is that SA experience provides a ground for students' authentic growth in which language development and personal and professional development are intertwined and mediated by a range of emotions and attitudes that are created, changed or confirmed in the process.

\section{Key words}

study abroad, language development, narrative frame, grounded theory.

* Corresponding address: Sanja Marinov, Faculty of Economics, Business and Tourism, Cvite Fiskovića 5, Split, Croatia. 


\section{INTRODUCTION}

Encouraged by an increasing number of students availing themselves of the opportunities provided by programmes such as Erasmus+ that aim at a greater internationalisation of higher education, study abroad (SA) has attracted much research attention in the last decades. For SLA researchers this has opened up an opportunity to study the potential of language development under specific and very diverse circumstances. Although some studies confirmed the commonsensical belief that SA context benefits participants' linguistic development because of regular exposure and contextualised L2 use opportunities lacking in their home context (Isabelli, 2007), others failed to support this claim (Riedel, 1989). Considering the multitude of potential interest areas and ensuing variables and their interrelatedness, the inconsistent findings in SA research are not entirely unexpected.

In this paper we explore university students' perception of SA, i.e. the ways in which they regard and experience language-related issues pertaining to their SA period. More specifically, we are interested in the role that language plays in the SA experience of Croatian non-language majors whose main interest/goal might not be increasing language proficiency. Since they are relative newcomers to SA, little is known of their profile. ${ }^{1}$ Also, there is a relative dearth of research on nonlanguage majors as compared to language students (Llanes, Arnó, \& Mancho-Barés, 2016) so we hope to add to this research. We first review relevant previous research and then present the results of our own study which utilises narrative frame (NF) to collect data and the abbreviated version of the grounded theory (GT) to analyse them.

\section{LITERATURE REVIEW: QUALITATIVE STUDIES ON LANGUAGE DEVELOPMENT IN SA CONTEXTS}

Due to space limitations, but also to the proliferation of SA research induced by "aggressive internationalization" of education (Cheng \& Fox, 2008: 38) it is impossible to provide a comprehensive review of previous research. ${ }^{2}$ Instead, we only briefly describe some linguistically-oriented studies that apply interpretative analysis methods to qualitative non-experimentally collected data.

One of the first SA studies that included the subjective component, conducted by Schumann and Schumann (1977), has inspired researchers to extensively explore personal variables in SA experiences, such as opportunities for language

\footnotetext{
${ }^{1}$ But see Bagić and Vrhovac's (2012) and Zlomislić, Gverijeri, and Bugarić's (2016) studies on intercultural competence.

${ }^{2}$ For more detailed reviews of SA studies see Freed (1998); Isabelli-García, Bown, Plews, and Dewey (2018); Kinginger (2009); Pellegrino (1998); Wang (2010); Yang (2016).
} 
learning and use, social distance, learner identity, and the causal relationships between those factors. The seminal longitudinal project following over 650 American students in Russia signposted the critical role of initial language proficiency in language development during SA and the fact that the ostensibly same SA context creates dissimilar opportunities for male and female sojourners (Brecht \& Robinson, 1993). This project also disclosed sojourners' need to assign meaning to their experiences. Hence, sojourners' SA accounts often entail their attitudes and beliefs about language, language learning, formal language instruction and SA, which affect their behaviour and subsequent language progress in SA (Brecht \& Robinson, 1995; Miller \& Ginsberg, 1995; Wilkinson, 1998). For example, sojourners do not readily seize various communication opportunities offered by the SA setting because they do not believe they could be beneficial (Miller \& Ginsberg, 1995), or because they resort to L1 or another shared L2 thus dispelling the myth that sojourners' language competence inevitably improves just by being exposed to more language input (Wilkinson, 1998). Similarly, sojourners refrain from L2 interaction and resort to L1 driven by the impression that their L2 skills are inferior compared to those of their peers (Pellegrino, 1998), or because they regard their social relationships as more important than language development (Slagter \& Pyper, 2019).

As demonstrated above, not all SA experiences are positive. To illustrate, Ayano (2006) found that Japanese sojourners in the UK suffered from homesickness and psychological fatigue, which led to their level of well-being remaining low for the whole sojourn. As a result, the negative feelings affected their language use and development.

Sojourners turn to their compatriots for social and emotional support and, consequently, interact in L1 driven by linguistic loneliness (Slagter \& Pyper, 2019: 51). Specifically, they are torn between the desire to interact with native speakers in order to grow linguistically and the need to relieve their loneliness, for which they lack the linguistic means. Despite their generally favourable SA perceptions, Turkish students in the US reported having experienced a language shock, language anxiety, or other negative feelings related to the interaction with the host community and access to language input (Guvendir, 2017). The findings highlight the disillusionment arising from the realization that SA "is not fundamentally, or in every respect, useful" (Guvendir, 2017: 43).

The amount and quality of language contact in SA contexts seems to typically fall short of sojourners' expectations and desires (Kimura, 2019; Kinginger, 2009). The determining factors of the amount of contact encompass learners' initial proficiency, native speakers' adjustment to their non-nativeness, and the lack of contact with native speakers. SA language development also depends on students' life histories, their objectives, the way they imagine themselves as language users, the qualities of their SA experiences, and their attitudes to these experiences (Kinginger, 2008). In other words, the individual differences found in language learning outcomes of SA are only partly attributable to the actual SA conditions. 
Since SA involves close contacts with another, sometimes very different culture, numerous cross-cultural issues arise that colour sojourners' experiences, views and identities. For example, while some of them never completely eliminate their initial ethnocentrism, the others develop close relationships with their host families and learn to value L2 for communication (Jackson, 2006).

Several SA studies (Cheng \& Fox, 2008; Pearson Evans, 2006; Swenson \& Visgatis, 2011) selected the GT approach as a data analysis method, ${ }^{3}$ because it "places great emphasis upon an attention to participants' own accounts of social and psychological events and of their associated local phenomenal and social worlds" (Pidgeon, 1996: 76). GT can be perceived as a method or as a theory. As a method, it involves continuous identification of meaning categories emerging from the data and the subsequent construction of a network of relationships between them. The final product of this procedure is a theory which attempts to explain the researched phenomenon (Strauss \& Corbin, 1998). GT allows for an analysis without preconceived categories and keeping an open mind to various theoretical directions indicated by data interpretation. Unlike content analysis, which defines mutually exclusive categories before data analysis, GT allows for categories to emerge from the data, they are not mutually exclusive and they change throughout the research process, which makes it suitable for underresearched phenomena.

Developing a GT requires the relationships between the identified categories to be incorporated into an underlying framework with one core category (Vollstedt \& Rezat, 2019). Strauss and Corbin (1990) differentiate between three types of data coding as parts of the process: open, axial, and selective. Open coding can be carried out at various levels (e.g. line-by-line, sentence-by-sentence, etc.) with smaller units of analysis producing more numerous descriptive categories that can later be combined into higher-level categories. In the process of axial coding the complex set of categories is investigated for relationships between them (Strauss \& Corbin, 1990), while the selective coding aims at designating one core category. This takes coding to a more abstract level where the core category is related to other categories from axial coding (Vollstedt \& Rezat, 2019). The result should be a coherent story that links all established concepts together. Vollstedt and Rezat (2019) underline that these procedures are not completely unambiguous and do not necessarily follow from each other chronologically but require the researcher to move back and forth between the data. Data gathering in GT is conceptualised as an ongoing process where new data are gathered continuously even when the existing data analysis has already advanced (Vollstedt \& Rezat, 2019). Since access to data is sometimes limited, an abbreviated version can be applied in which researchers depend on the original data (Strauss \& Corbin, 1998). Pearson-Evans's (2006) GT-based analysis of the dynamics of sojourners' cross-cultural adjustment and learning indicated three themes: social networks, food, and language. The themes symbolised the core aspects of participants' struggle to find balance

\footnotetext{
${ }^{3}$ Interestingly, Ayano (2006) intended to apply GT, but decided to abandon it due to its complexity and time constraints and opted for thematic data analysis, still keeping the three stages envisaged by GT.
} 
between their home culture, host culture and other foreign cultures they encountered. Participants' confidence gradually increased and while it was possible to identify the common stages of cross-cultural adjustment, the individuals differed greatly in terms of when they entered each stage and how long it lasted.

In their attempt to identify factors affecting acculturation of in-coming students at Canadian universities, Cheng and Fox (2008) arrived at seven key categories within three themes. One among many interesting findings indicated that students felt intimidated by their L1 peers, often because they perceived their own L2 competence as inadequate. As a consequence, they felt they were missing out on opportunities presented by the SA setting. Again, students' language proficiency prior to SA proved to be one of the key elements of successful acculturation and academic engagement.

The only SA study applying NFs was conducted by Swenson and Visgatis (2011). ${ }^{4}$ Their analysis of overseas experience of four Japanese students yielded the following 12 themes: reasons for joining program; preparation; internship tasks; satisfaction and dissatisfaction with the program; personal effort during the internship; personal improvement through the program; free time activities; host family experience; overall view of program upon return, and general and specific suggestions for next year's students. Areas requiring improvement were indicated accordingly.

\section{METHODOLOGY}

\subsection{Instrument}

The instrument for eliciting data was an NF in the participants' L1 (for an example of a completed NF see Appendix 1).

$\mathrm{NF}$ is a written story template consisting of incomplete sentences followed by blank spaces which participants complete thus creating a coherent story about their own experiences and ideas (Barkhuizen, 2014). Thus, the narrative form is preserved while overcoming the problem of participants' likely lack of familiarity with the genre of reflective journals or simply lack of ideas about what and how to write (Barkhuizen, 2014). The provided sentence starters, transitions, or time and place references are anchor points equipping participants with scaffolding in terms of the structure and content of their narrative. NF prompts warrant that data collected are not too dispersed or irrelevant but are followed by unlimited space to leave enough leeway for participants to write in their own experiences. In the analysis, data collected via NFs speak for themselves and lead researchers through

\footnotetext{
${ }^{4}$ For a review of SLA studies using NFs see Barkhuizen (2014).
} 
the processes of uncovering concepts and developing theories. Finally, NFs are versatile: they can be created to suit particular research needs.

Our decision to apply NFs was mainly driven by the need to overcome the rigidness of questionnaires, where the content and expected answers are largely pre-set, and by the wish to elicit a relatively structured and thus comparable data. To benefit from the above listed advantages, the NF design must be well-thought out and the ensuing data interpretation careful, accurate and comprehensive. The design and administration features (Barkhuizen, 2014: 21-22) necessary for NFs to be effective incorporated in our study are as follows:

(1) Purpose refers to the research question the study aims to answer and to the type of data it is trying to elicit with this aim in mind. The purpose of this NF was to capture students' experiences and perceptions of language learning in an SA situation. It was clearly presented to the students in the introductory letter accompanying the NF.

(2) Topic must be clearly defined and summarised in the title or explained in the instructions. The title of our NF was "A story about my Erasmus". The topic was introduced to the respondents in written form in the introductory letter.

(3) Experience: The NF must encourage the participants to talk about their lives, their actual experience, whether it refers to the past, present or future. Our NF targeted students' experience in English language learning and was designed to elicit topic-related preferences, habits, actions, thoughts, or feelings they experienced before, during and after SA.

(4) Reflection: The NF should encourage the participants to explain or evaluate the experiences they shared, which usually includes emotions or beliefs. Our frame elicited these by using prompts such as "I think it is because ...", "I believe that ...".

(5) Spatial and temporal dimension: The NF should be fully contextualised, i.e. the elicited story must be located in a particular place and it must have a clear time frame. Our NF starts with the pre-SA language-related experiences and beliefs, moves to the SA language-related experiences and perceptions, and ends with the conclusions and goals for the future.

(6) Coherence: The NF should not result in a list of facts or answers to questions but should read as a coherent story. In our NF, coherence was achieved by careful selection, formulation and placement of anchor points.

(7) Formatting: The NF should be formatted like an incomplete story consisting of paragraphs and not like a list of prompts one below the other. Our NF contains 9 clearly marked paragraphs with 35 anchor points distributed logically across the space producing a prose form.

The following are three administration features: 
(8) Instructions should be clear and detailed. Because our NFs were administered electronically, written instructions explaining the purpose of the study and the procedure of completing the NF were attached.

(9) Trialling: NFs should be trialled prior to their administration in order to eliminate any possible misunderstandings. Our NF was trialled with a focus group from a similar population, who were invited to comment on all aspects of the frame (i.e. content and formulation of the anchor points, technical details and formatting). All constructive comments are reflected in the final version of the frame.

(10) Language: The language choice depends on several factors. We opted for the participants' L1 (Croatian) because we believed they would be better able to express nuances of meaning and more willing to participate.

\subsection{Participants and data collection}

Students who had recently returned from their Erasmus mobility programmes were contacted via the student mobility offices at two Croatian universities. They received NFs in .docx format which allowed them to freely exploit the empty spaces following the prompts. The frame was preceded by a letter explaining the purpose of the NFs and specifying instructions for its completion, and followed by a questionnaire eliciting demographic information (see Appendix 2).

We received 33 NFs completed by participants from a range of study programmes: economics, tourism, medical studies, maritime studies, physics, kinesiology, law, agriculture. Their host countries were: the Czech Republic, Finland, France, Germany, Italy, Poland, Portugal, Slovenia, Spain, and Sweden.

The sojourns mostly lasted a semester (about five months), but some were 712 months long if participants spent two semesters abroad or had multiple Erasmus experiences. Participants were undergraduate or graduate students in their final study years. Two participants had both Erasmus study and internship experience and three conducted research for their theses.

\subsection{Data analysis}

Both authors analysed individual frames as complete stories following the general principles of the abbreviated version of GT analysis (Charmaz, 2006), i.e. we coded and constantly compared the original data only (NFs).

In the first stage, open coding, we identified and coded the salient concepts and organised raw data into emerging themes. We started by individually reading all NFs as full stories giving labels to observed phenomena. Then, we collaboratively reiterated the procedure: we re-read and relabelled the frames if needed, and compared the NFs to each other, going back to the whole story 
whenever necessary until we reached agreement. First the lower-level categories emerged, which we subsequently integrated into more abstract meaningful units, i.e. higher-level categories.

In the axial coding stage, the relationships between the proposed categories were considered through a complex network and overarching concepts identified. In the final, selective coding stage, we identified the core category, i.e. the central concept to which all others relate.

\subsection{Results and discussion}

Given the specific character of GT analysis the findings are discussed along with the process of deriving higher-level categories from the lower-level ones, determining their relationships, describing the complex network of SA outcomes as resulting from these NFs, proposing the three categories of axial coding, and finally discussing the suggested selective code.

\subsubsection{Open coding}

In the open coding stage, all observed phenomena were coded: descriptive labels were assigned to particular phenomena and low-level categories were identified (for an example of a coded NF see Appendix 1). The identified themes are elaborated and illustrated by the quotes from the NFs. Frequencies of the answers are reported where appropriate. In the examples provided, participants' own words are in italics.

Given the complexity of this NF which taps into three main themes - pre-SA circumstances, characteristics of SA language use, and SA outcomes - each with its sub-themes, the results are presented in corresponding sections.

\section{Pre-SA state of affairs}

The open codes for this theme pertain to two main sub-themes: 'pre-SA English language learning experience' and 'SA goals'. The analysis of students' perception of their pre-SA English learning experience resulted in the following low-level categories: 'the role of media', 'informal language learning', 'formal language learning', 'the role of maturity in language learning', and 'perception of (own) preSA L2 proficiency'.

For most participants, the easiest way of learning English in the pre-SA period was from media or by being engaged in informal language usage. Their preference was based on the belief that regular exposure to language enhanced memorisation and provided a good pronunciation model, as well as interesting, varied and relevant input. Participants stressed the important role of interlocutors and the belief that language is best learnt if regularly used in spoken interaction (1). 
(1) The most difficult way of learning English was when we studied grammar in a traditional way, while the easiest way was learning through conversation, by talking to people. It is because in that way I always learn something new and by regular use I improve my English.

Participants perceived language learning in a formal educational context as difficult for various reasons. As young beginners, they lacked the knowledge to use language in communication. In secondary school the difficulty-inducing factor was the demanding programme/teacher, and at university it was the language for specific purposes (LSP). Several participants felt learning English became easier at university due to external reasons (e.g. a motivating programme/teacher) or internal ones (e.g. good pre-knowledge or maturity). Participants also perceived their maturity as the deciding factor that enabled them to engage in communication or self-regulated learning (2).

(2) The most difficult way of learning English was studying grammar and at the beginnings of learning English, while the easiest way was when I became more mature. It is because I started researching ways of autonomous learning and the resources for such learning became more available.

The category 'perception of (own) pre-SA proficiency' includes two sub-categories: 'strengths in language skills' and 'weaknesses in language skills' (Table 1). The frequencies present the overall number of times a skill was mentioned although there was great variation in individual answers, ranging from listing none to all skills. Speaking was most frequently seen as a strength, which indicates participants' perception of themselves as fluent and able communicators in English. Two factors may attest to the credibility of this: first, English is indeed widely spoken as a foreign language in Croatia, and second, students who think they have an inadequate level of language proficiency do not apply for SA. Grammar was perceived as the most problematic area. Interestingly, vocabulary was not positioned high on either list. Listening was mentioned only once as a weakness, although it might have been implied by the term 'comprehension'. As for writing, it was not clear whether participants referred to writing structured texts (e.g. essays) or simply the mastery of spelling. It could be speculated that these perceptions reflect the aspects emphasised in formal teaching participants had been exposed to. There is only one mention of LSP, which may reflect the lack of exposure to it across our sample. 


\begin{tabular}{|l|r|l|r|}
\hline \multicolumn{2}{|l|}{ PRE-SA STRENGTHS AND WEAKNESSES IN ENGLISH LANGUAGE PROFICIENCY } \\
\hline STRENGTH & $f$ & WEAKNESS & $f$ \\
\hline speaking & 12 & grammar & 15 \\
\hline writing & 10 & writing & 3 \\
\hline reading & 7 & spelling & 3 \\
\hline comprehension & 7 & foreign language anxiety & 3 \\
\hline grammar & 5 & pronunciation & 2 \\
\hline vocabulary & 5 & LSP vocabulary & 1 \\
\hline all & 2 & vocabulary & 1 \\
\hline & & listening & 1 \\
\hline
\end{tabular}

Table 1. Students' pre-SA strengths and weaknesses in English language proficiency

The open codes for the sub-theme 'SA goals' revealed 12 low-level categories grouped into 'linguistic goals' and 'non-linguistic goals' (Table 2). Although linguistic goals were important, the non-linguistic ones outnumbered them significantly. Most students sought new experiences, which included learning about the diversity of new destinations and cultures and making new acquaintances. Looking for a challenge was featured in both non-linguistic and linguistic groups of goals (3 and 4).

(3) I decided to apply for study abroad because I wanted to leave my comfort zone, test my abilities and see how well I can cope in a new environment. I also wanted to see how another educational system works and to meet people who are different from me.

(4) I decided to apply for study abroad because I wanted to acquire new knowledge, experience and acquaintances and to see how well I can cope in a new environment with a language barrier.

Most language goals referred to English as the participants' only or strongest L2. Students believed their proficiency would improve through daily academic exposure because English was the language of instruction at the host institutions. The goals reflect the importance of using English as a lingua franca and its role as an intermediary in achieving non-language related objectives. Mastering a language other than English (hereafter L3) does not feature as very important in pre-SA goals. 


\begin{tabular}{|l|r|l|r|}
\hline \multicolumn{3}{|c|}{ SA GOALS } \\
\hline \multicolumn{1}{|c|}{ LINGUISTIC GOALS } & $f$ & NON-LINGUISTIC GOALS & $f$ \\
\hline improve L2 & 13 & new experience & 21 \\
\hline learn L3 & 3 & new academic experience & 17 \\
\hline challenge & 2 & challenge & 7 \\
\hline lower language anxiety & 1 & affective & 5 \\
\hline & professional development & 3 \\
\cline { 2 - 3 } & personal development & 3 \\
\cline { 2 - 3 } & increase employability & 3 \\
\cline { 2 - 3 } & more opportunities & 1 \\
\hline
\end{tabular}

Table 2. Students' goals for SA period

\section{Characteristics of SA language use}

The analysis of the participants' SA language habits uncovered a number of personal and contextual factors influencing their language use. Practically all NFs revealed a substantial increase in the use of English: all participants used it daily both in informal and formal academic contexts. The open codes for this theme encompassed the following three sub-themes: 'ease and difficulty of SA language use', 'the role of interlocutors', 'the role of L3'.

The open codes pertaining to the 'ease and difficulty of SA use' resulted in the lower-level categories: 'formality of the communication context', 'interlocutors', 'complexity of topic', 'stage of sojourn', and 'language-related strategies'.

Participants found it easier to use English in informal than in formal situations (5), when talking to their peers rather than to lecturers or native speakers, when talking to people whose language proficiency was equal to or better than theirs, and in routine conversations rather than when trying to express more complex ideas. The difficulties were more pronounced at the onset of the SA period and were attributed to the novelty of the situation and the need to alleviate L2 anxiety, and generally adapt and become more relaxed about using English.

(5) It was easy to use English in everyday spoken communication, and it was difficult to use English at the university, when we were assigned academic reading on a very specific topic. It is because I didn't have much previous experience with that type of literature.

Participants who had difficulties with using English in formal learning situation most often complained about their insufficient knowledge of LSP, which they had little exposure to in their pre-SA period (6), or had not fully mastered. Several 
students attributed it to general L2 anxiety or its particular form associated with formal situations in which students had to address people in authority.

The SA context calls for the employment of language learning strategies (LLSs) to cope with novel language learning situations, and for the employment of communication strategies to manage problems arising in genuine interaction with a variety of interlocutors. Although some researchers insist on distinguishing between language use and language learning strategies, we share the belief that communication strategies can also support language learning (Oxford, 2017). In SA it is often impossible to clearly differentiate between communication and learning strategies since they often perform a dual role (6). To cover all strategy types, we use the term language-related strategies.

(6) In a conversation when I didn't fully understand my interlocutors I'd ask them to explain the words and that's how I learnt them.

One NF paragraph prompted an explanation of what students did when facing a language problem. The codes for this low-category therefore encompass a range of language-related strategies, as explained and illustrated below.

When participants did not understand their interlocutors' message they most frequently and naturally asked for repetition and/or clarification (7).

(7) In a conversation when I didn't fully understand my interlocutors I'd ask them to repeat or explain their sentence.

When faced with an unknown expression, students also guessed from the context, referred to an external resource/Internet, asked for help, mimed, and switched codes (8).

(8) In a conversation when I didn't fully understand my interlocutors I'd try to use body language to elicit an explanation or we'd try another language.

When they failed to recall a language item in speaking or writing, students again primarily turned to the Internet sources if the situation permitted it, asked for help, or used circumlocution (9).

(9) On the other hand, when I wasn't sure how to say or write something I used the Internet, if there was time. But if the communication was fluent I tried to express myself using synonyms. Everything can be said in many ways.

Many of the identified strategies can be classified as LLSs but they were primarily used to meet a communication need and manage a communication problem. Hopefully, in some instances learning took place, too. The opportunities for applying those strategies were certainly abundant. 
As shown earlier, students' perception of the important role of interlocutors varied greatly. Therefore, it is recognised as a separate sub-theme of the Characteristics of SA language use with the open codes including the following lowlevel categories: 'attitudes and emotions induced by encounters (with different interlocutors)', 'self-assessment and peer-assessment of English language proficiency (ELP)', 'perceived impact of ELP on communication', and 'perceptions of English native speakers'.

Understandably, nearly half of participants noted that they preferred communication with their peers, in particular other Erasmus students because of the shared interests (10), but also because they saw it as an opportunity to practice English in a relaxed environment.

(10) I preferred to communicate with foreign and local students at the University because I felt we were members of the same community.

Although none were in an English-speaking country, some participants preferred talking to English native speakers or more proficient English users, who were perceived as good language models and immediate and trustworthy sources of error correction. This is why some students preferred communicating with an authority, but others, as previously noted, may have felt anxious in such situations.

Almost half of the participants felt their own proficiency was superior to their interlocutors' and attempted to avoid communication with poor English language users, which was not always possible because these were local residents or service personnel. However, several students emphasised that any communication was an important part of the SA experience, and some saw it as a learning opportunity, a kind of a "language playground" where they could learn from each other (11).

(11) The English used/spoken by my interlocutors was average - there were people who had only the basic English knowledge and those who were native speakers. A wide range of different users. This was an excellent opportunity for learning the language from each other.

Evidently, many participants set out to improve their English during the SA period or were bound to use it as a lingua franca given the international context. Nonetheless, this context also offered numerous possibilities of encountering and/or using an L3. The open codes for this sub-theme included the low-level categories 'learning the language of the host country', 'attitudes and emotions triggered by L3 use' (12), 'L3 as a communication strategy' (8), and 'futureoriented decisions concerning foreign languages'.

(12) I preferred to communicate in Swedish because the University of Gothenburg provided a free course of Swedish so I felt the need to show appreciation by using the language they taught me. 


\section{SA outcomes}

The final paragraphs encouraged participants to reflect on the SA outcomes in terms of 'achievements/underachievements' and any 'lessons learnt'. The open codes for the sub-theme of 'achievements/underachievements' include 14 items distributed into three categories: 'linguistic achievements', 'linguistic underachievements' and 'non-linguistic achievements' (Table 3).

\begin{tabular}{|c|c|c|c|c|c|}
\hline $\begin{array}{c}\text { LINGUISTIC } \\
\text { ACHIEVEMENTS }\end{array}$ & $f$ & $\begin{array}{c}\text { LINGUISTIC } \\
\text { UNDERACHIEVEMENTS }\end{array}$ & $f$ & $\begin{array}{l}\text { NON-LINGUISTIC } \\
\text { ACHIEVEMENTS }\end{array}$ & $f$ \\
\hline speaking & 20 & grammar & 12 & personal growth & 9 \\
\hline vocabulary & 10 & reading & 2 & professional growth & 3 \\
\hline LSP/LSP vocabulary & 8 & spelling & 2 & all aspects & 3 \\
\hline writing & 5 & writing & 1 & & \\
\hline pronunciation & 4 & (informal) speaking & 1 & & \\
\hline fluency & 4 & vocabulary & 1 & & \\
\hline comprehension & 4 & LSP vocabulary & 1 & & \\
\hline grammar & 3 & & & & \\
\hline reading & 1 & & & & \\
\hline complexity & 1 & & & & \\
\hline
\end{tabular}

Table 3. Post-SA achievements/underachievements

The majority believed that their English improved, at least to some extent, and attributed it to the regular English use, challenges in using English presented by novel situations (including formal academic ones), the duration of exposure, absence of L1 speakers and opportunities for error correction. Several students, however, attributed it to their personal characteristics: personal efforts, absence of L2 anxiety, or fear of making mistakes. As expected, most students felt their speaking (also referred to as communication or oral communication) improved. Other important areas of improvement were vocabulary and LSP (13).

(13) I improved my conversational English and mastered the professional vocabulary related to my graduation thesis, but I didn't improve my grammar.

The 'non-linguistic achievements' often included aspects indirectly related to language (use), such as reduced L2 anxiety, which was not only perceived as facilitating language development but also as a gain per se and was thus considered an aspect of personal growth. Likewise, improvement in presentation skills and public speech was perceived as a language-related element of professional growth. 
The perceptions of underachievement refer only to language. Most participants believed they made no progress in their English grammar, which they attributed to the characteristics of the context, i.e. prevailing spoken communication, where fluency was more important than accuracy, the need to adapt to their interlocutors with lower English language proficiency, and no formal English language courses. Two students attributed it to their own beliefs and selfperception: grammar requires rote learning, which they dislike, or they see themselves as highly proficient grammar users whose progress is slow or unnoticeable.

Students attributed their underachievement in spelling to the prevalence of spoken communication and the inherent characteristic of English spelling. The interlocutors' poor English language proficiency was indicated as negatively influencing vocabulary development and informal speaking, while underachievement in LSP vocabulary was attributed mainly to the fact that its usage was restricted to academic contexts.

The final paragraph of the NF induced participants' reflection on the SA experience as a whole and guided them into drawing conclusions that may direct their future decisions or activities generating the sub-theme of 'lessons learnt'.

Participants' language-oriented conclusions include these open codes: 'languages serve as an intermediary in gaining new knowledge and new acquaintances' (14), 'language is best learnt in communication and regular use, effort is needed to learn a new language' (15), 'L2 anxiety prevents progress and one should not be afraid of making errors or asking for help', 'fluency in several languages is more important than accuracy in only one'.

(14) What I learnt from this experience is that proficiency in foreign languages opens the doors to new acquaintances and new knowledge so I believe that in the future I'll invest in improving the languages I already speak but also take up new languages.

(15) What I learnt from this experience language-wise is how easy it is to "soak up" a language and at the same time how difficult it is. How easy it is to reach the point of understanding a language and still being hardly able to put together a simple utterance. I feel I've acquired English without actually studying it in a traditional way, from course-books. Only by learning another foreign language have I learnt how important it is to learn how a language "breathes", how much culture influences it, how to use particular verbs, ... generally how hard one must work to learn a language properly. Therefore, I believe that in the future I will work hard and, with pleasure, continue communicating and using languages.

The non-linguistically-oriented conclusions included 'challenge is important for progress' (16), 'any improvement must be driven by setting and complying with high standards', 'there is always room for improvement', 'cultural differences are endless and interesting', 'one can become more independent during SA', 'one can get to know oneself during SA'. 
(16) What I learnt from this experience is that one must be willing to get out of his/her comfort zone because that opens so many opportunities so I believe that in the future I'll be even more open to new opportunities because they make us better people.

Accordingly, participants concluded that they increased cultural sensitivity and improved their idea of multiculturalism (17), that they would reduce speaking anxiety, look for opportunities to use language regularly, try to travel more, seek similar opportunities, and take up new L2s.

(17) Living, working and studying in a multicultural environment is really priceless and I believe it adds to my personal development. Living in a dormitory like I did during my SA presents you with rare opportunities of living with people of so many different nationalities. There's no better way of discovering the story of internationalisation and multiculturalism than sharing a space (room, toilet, kitchen) with people of different nationalities.

If they could relive the experience they would do it earlier (in course of their study programme), change the destination or look for more challenges (e.g. work opportunity) because it was an unforgettable experience. Nevertheless, the benefit of the experience did not come without an emotional cost and investment and was deemed acceptable only as a temporary lifestyle (18).

(18) What I learnt from this experience is priceless, definitely one of the most valuable life experiences so far so I believe that in the future I'll try to find more similar opportunities because nothing can replace this experience, no book or theory. If I could repeat the study abroad experience, I'd probably use that opportunity but I'd always want to come back home too, probably exactly because I'll never be able to express myself in any language as well as I can in my own.

\subsubsection{Axial coding}

This section presents the results of the second stage of the analysis, i.e. axial coding, which requires forming relationships between the categories. We first identified the high-level categories resulting from a range of low-level categories. This is depicted in the three illustrations below, each for one of the three main themes contained in the NF.

Figure 1 shows four high-level categories pertaining to the pre-SA period that have resulted from the low-level categories described in the preceding section. These include participants' beliefs about language learning emanating from their experience as language learners, attitudes and emotions related to past and upcoming SA experience, and finally the search of novelty and progress. 
Theme: Pre-SA state of affairs

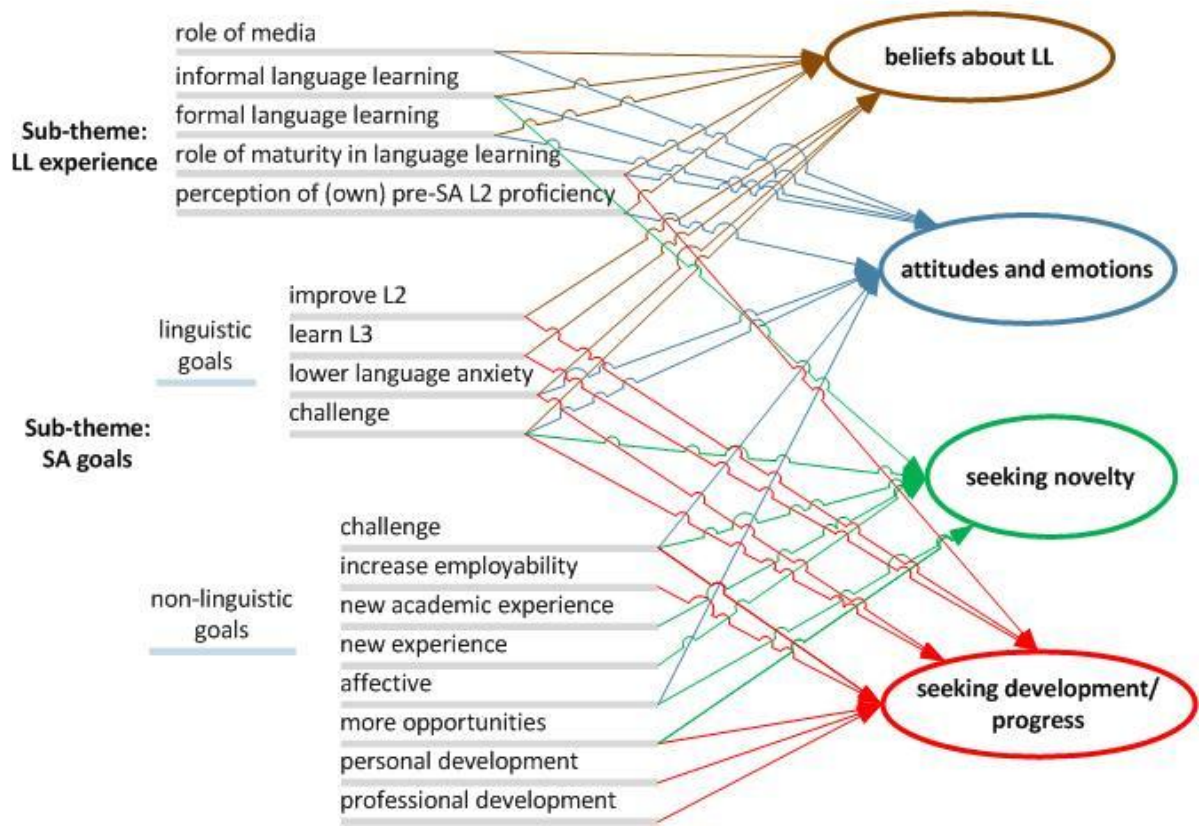

Figure 1. Low-level categories of the theme pre-SA circumstances integrated into high-level categories

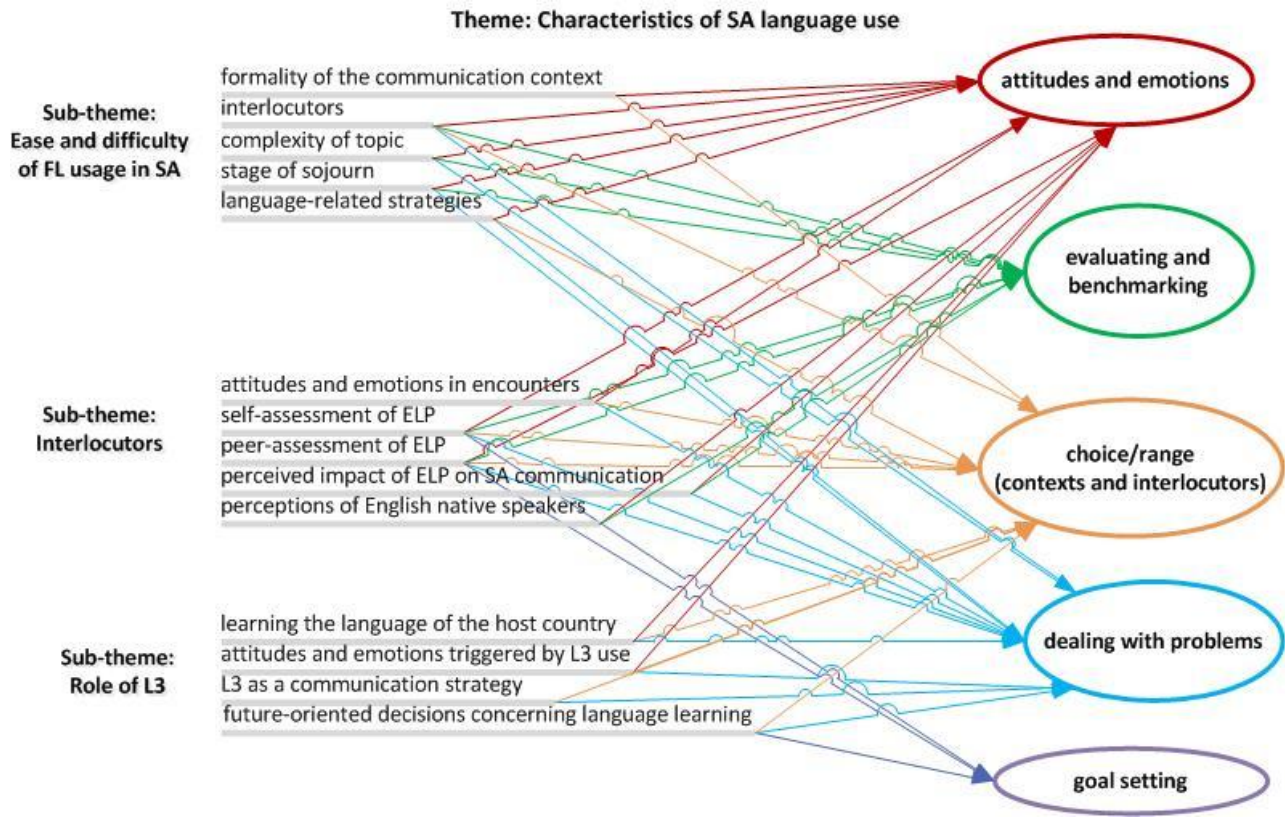

Figure 2. Low-level categories of the theme characteristics of SA language use integrated into high-level categories 
Figure 2 above illustrates participants' perceptions about the experience of SA language use as captured by several low-level categories subsequently integrated into five higher-level categories: attitudes created/confirmed and emotions involved, evaluations made and benchmarking performed, increased range of contexts and interlocutors, ways of tackling problems, and setting new languagerelated goals.

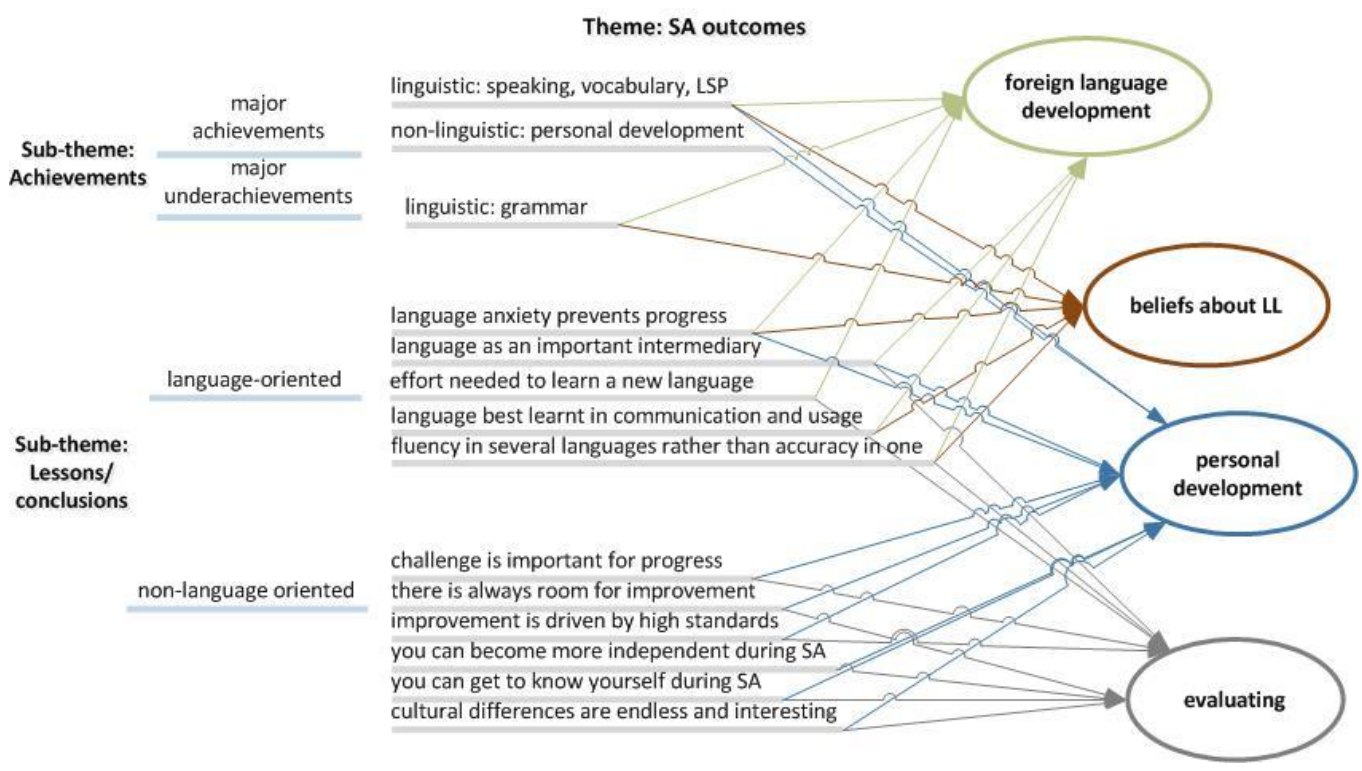

Figure 3. Low-level categories of the theme SA outcomes integrated into high-level categories

Figure 3 depicts the relationships between the low-level categories of the theme SA outcomes and the ensuing high-level categories. The perceived language outcomes evidently show that progress in language proficiency has taken place, beliefs about language learning have been confirmed and/or expanded, personal development has taken place, and participants have had the opportunity to critically consider and evaluate people, places and events.

Considering all low-level categories and the ways they participate in the highlevel categories creating a complex network of relationships we conclude that all of the identified concepts can be summarised into the following three categories: 1 ) language development, 2) personal and professional development, 3) attitudes and emotions (Figure 4). As shown above, the identified three principal categories present in the NFs are strongly interconnected and often overlap in students' SA experience. Example (19) combines elements of positive attitude towards the experience, description of a combination of linguistic and non-linguistic achievements, and finally a positive attitude towards this achievement, (20) illustrates an average language achievement but where elements of language and emotions participate in personal growth, and (21) illustrates a positive attitude towards all aspects of growth enabled by SA experience. 
(19) As for the classes I'm happy with the courses delivered in English, I learnt how to explain things and give my opinion in the fields I'll hopefully be working in, which highly motivated me.

(20) After study abroad my English has somewhat improved but not significantly, but I've become more self-confident in conversations.

(21) I made progress in every aspect of my life, language skills, professional knowledge, personal growth, independence, skills of living abroad, and dealing with real-life situations Erasmus brought me.

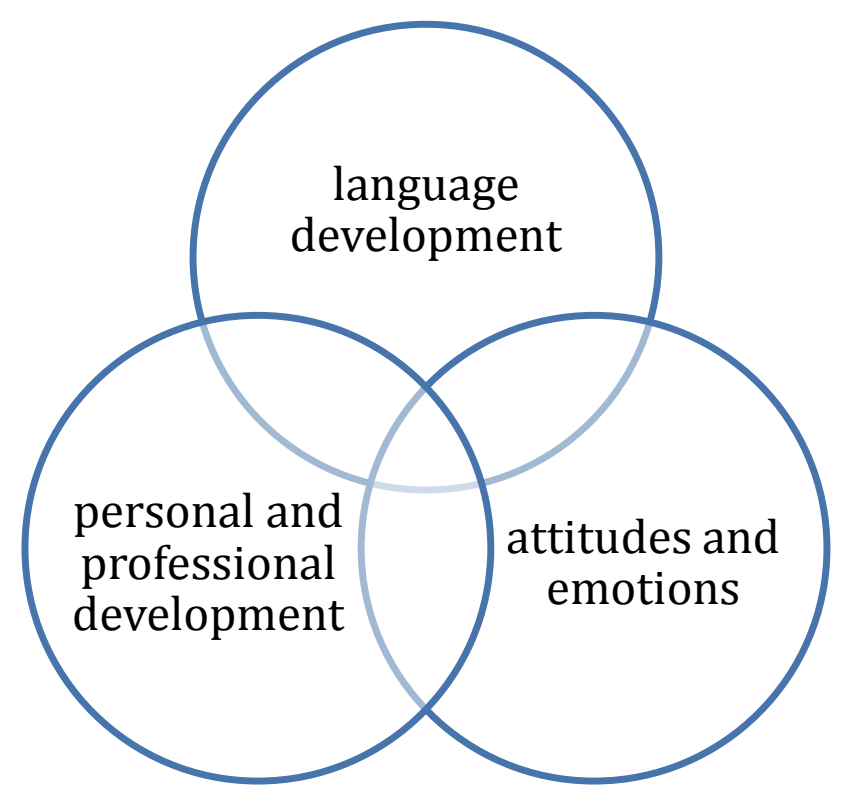

Figure 4. The three categories resulting from axial coding

Figure 5 illustrates the complex and intensive process of identifying the connections between the categories as it unfolded during our discussion in the analysis. 


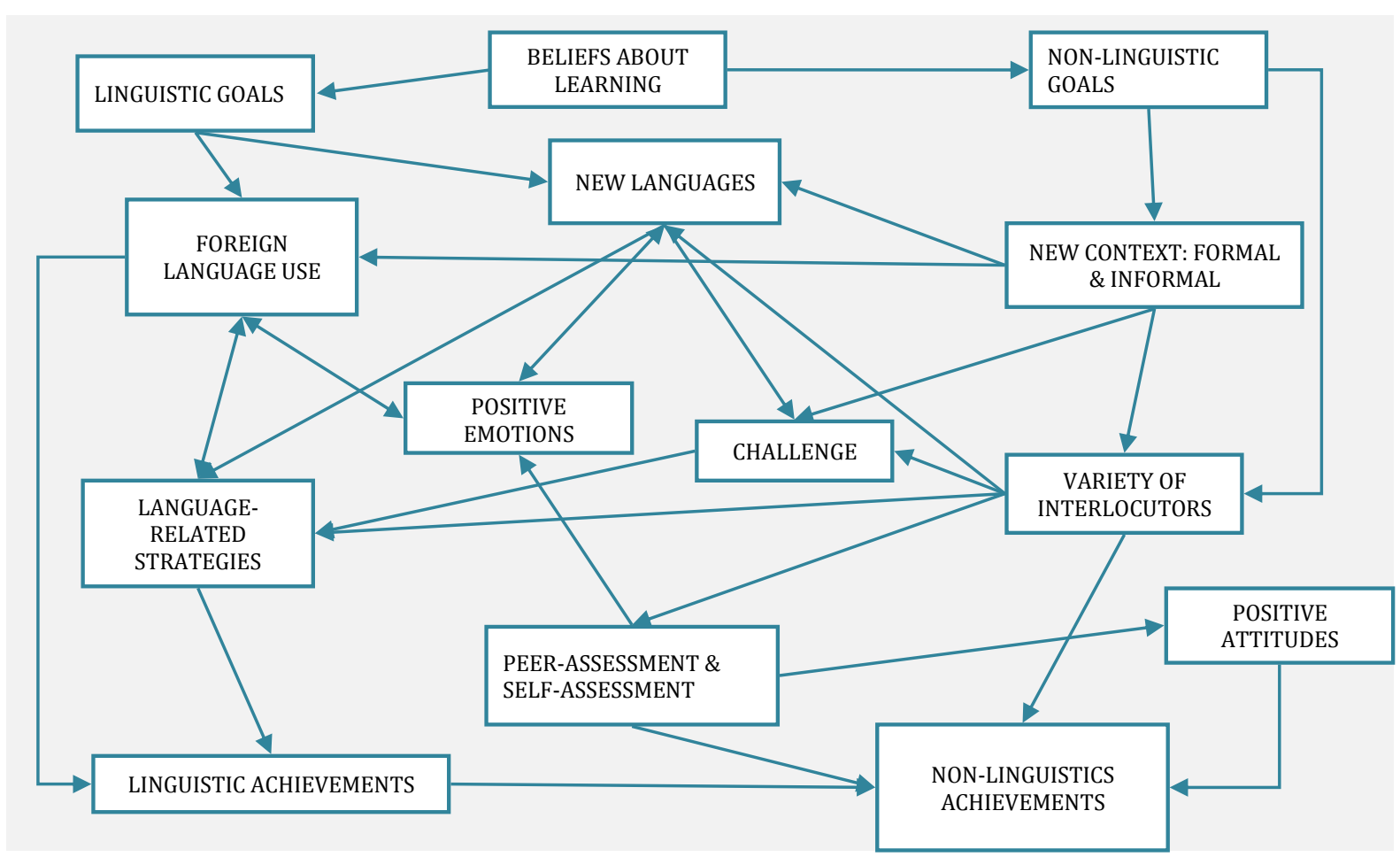

Figure 5. The sketch of mental process of axial coding leading to the three categories in Figure 4

The drawing represents the web of interconnected concepts. Students, experienced language learners/users who believe language is best learnt if used regularly, especially in communication, set linguistic and non-linguistic goals for their SA period. They perceived SA as a unique opportunity to actively engage in language use in both formal (academic) and informal (non-academic) daily routines. The non-linguistic goals - seeking new acquaintances, new opportunities, and challenges in living in a new environment - led to many communication opportunities. Specific requirements of the educational context, in particular the use of English for academic and specific purposes, forced students to use registers and genres that they previously rarely encountered. This led to linguistic achievements but also personal and professional development. The novel context provided a large number of interlocutors, mostly members of the shared community with similar interests who were concomitantly a source of knowledge of the world, of diversity, and of multiculturality. Interactions with new interlocutors, regardless of their proficiency level, generally proved to be beneficial for SA participants because they presented a challenge and opportunities for practice. Finally, the context induced the employment of numerous language-related strategies with the purpose of managing communication or language learning. The initial positive expectations of the experience were met or even exceeded, which led to personal and professional 
development. This was mediated by an array of opportunities in which students were able to evaluate their abilities by comparing themselves to their peers or by using other benchmarks, such as an academic task completion or success in coping with daily routine situations. Regular use of language facilitated the development of fluency, which triggered positive emotions and anxiety relief. This in turn encouraged language use and led to more communication opportunities. More frequent language use meant a greater need to apply language-related strategies enhancing opportunities for learning. Most participants used English as a lingua franca but various possibilities of using L3 were present, too. Given the short period of the SA sojourn, achievement in L3 was limited but generated favourable attitudes and decisions regarding participants' language repertoire.

\subsubsection{Selective coding}

Selective coding, the last stage in the GT approach, aims at identifying a concept that connects all elements of the SA experiences described in NFs. It does not imply disproving the highly individual nature of SA experiences but serves to identify an idea emanating from all categories and their relationships. Thus, one theme emerged as permeating all others: authenticity of growth. The high-level categories resulting from the open coding and paving a way to the process of axial coding with the resulting three categories indicate that the SA context was conducive to creating attitudes and shaping emotions, which enabled students to develop, i.e. grow in a number of areas. What is special about this growth is its authenticity, which is seen as sojourners' development that unfolds in ways and directions that represent the true nature of their (and not somebody else's) experience. Expectations externally imposed on sojourners may be far less important for the overall outcomes (whether linguistic or non-linguistic) of SA than sojourners' needs and beliefs about the benefits of the situation, prior and current experiences, personal evaluations of the environment and their own position in it, attitudes generated, and emotions involved in the process. This is in line with Taylor's stance that:

\footnotetext{
"there is no such thing as an abstract quality of "authenticity" which can be defined once and for all. Instead we should acknowledge that authenticity is a function not only of language but also of the participants, the use to which language is put, the setting, the nature of the interaction, and the interpretation the participants bring to both the setting and the activity." (Taylor, 1994: 4)
}

Bearing in mind that the forms of authenticity characteristic of the growth sustained by SA are all strongly intertwined and essentially inseparable, we now attempt to outline them to clarify the proposed conclusion. 
Authenticity of choice. Students have chosen to study abroad based on their own intuitions or expectations created following other students' accounts about what kind of experience it is. It is their genuine decision based on the set of beliefs they had developed.

Authenticity of beliefs. Students' goals and pre-SA beliefs indicate that they believe language is best learnt by regular use and in communication with others. They also believe they can learn and broaden horizons by encountering diversity, by learning from other people and their cultures. The SA experience provided support to these beliefs (22).

(22) I preferred to communicate with all new people and professors because it was very interesting to hear new ways of thinking. I [didn't avoid] communication, although I initially felt uneasy because I went there to gain new experience and knowledge and by avoiding speaking English I would have not achieved that.

Authenticity of purpose. This refers to students' needs portrayed in our NFs as goals they want to achieve. They defined the purpose of their stay autonomously based on the prior experience and beliefs they hold about language learning and opportunities that are conducive to progress and development in general. The analysis showed that seeking novelty and challenge were seen as important drivers of growth.

Authenticity of language use. Even if the goals students set for their SA are nonlanguage-oriented, they are bound to use an L2 (predominantly English). Unlike in language classrooms, where efforts are invested in order to "create contextual conditions that are appropriate to them [students] and that will enable them to authenticate it as discourse on their terms" (Widdowson, 1998: 712), language in SA is used for genuine purposes. The students refer to them as "real life situations": meeting academic requirements, establishing contact with peers, and managing daily routines. Also, by participating in a multilingual community students encounter and use L3s too, either with a goal of learning/practicing them, or as a language-related strategy imposed by the context.

Authenticity of context. For the language use to be authentic it has to be localised within a particular discourse community (Widdowson, 1998). As our data show, participants move to a different country but they retain their role of students pursuing academic education. Accordingly, the most likely interlocutors they seek and encounter are their peers with whom they are strongly connected as members of the shared community, with common problems and topics for discussion. Inevitably, they also interact with their lecturers and the presented study material. Thus, new discourse community (Swales, 1990) is created which provides grounds for the authentic language use. Communication is inseparable from the community and "contexts are constructed out of the local knowledge of particular 
communities" (Widdowson, 1998: 708). The use of language is thus localised, i.e. focused on the things familiar in the community they belong to. In SA students' discourse community language use may be limited by the interests of a specific age bracket and academic interests, but may be broadened by the encounter of many different cultural backgrounds.

\section{CONCLUDING REMARKS}

The all-encompassing idea that emerged from the analysed content was authenticity of growth. It is evident that growth does take place in SA period and is mediated by a number of factors including students' authentic choice to participate in the experience, beliefs about learning and development, the purpose of their stay, the language use, and the context.

In line with previous research (Kinginger, 2008) our study confirms the idea of SA being an encouraging yet "patchy" environment for improving language competences. Ideally, in order for SA to prove a useful environment for L2 acquisition participants should be immersed in regular interactions with competent native speakers who can support their language acquisition but such experiences are rare (Wang, 2010). Our data demonstrated that interlocutors were very important regardless of their language proficiency level: highly proficient interlocutors proved to be valuable role models, but less proficient interlocutors provided ground for negotiation of meaning. The preferred type of interlocutors, i.e. other Erasmus students of mixed language proficiencies and nationalities, created a new discourse community with shared interests and concerns presenting an environment conducive to frequent communication driven equally by affinity and convergence as well as by novelty and challenge. Finally, sojourners do not see themselves as language learners only (Kinginger, 2009), but also as young professionals aiming at gaining personal independence, intercultural experience, and academic competence (Benson, Barkhuizen, Bodycott, \& Brown, 2013). The astonishing range of topics emerging from NFs in our study suggests that SA is more than a language learning experience and includes other numerous cognitive, cultural, social, affective and personal experiences and perceptions.

We hope to have added to the knowledge of the immensely complex phenomenon of SA by applying and fully describing the GT analysis, the results of which pointed to new concepts, processes and relationships pertinent to SA experiences. We also hope to have contributed to the methodology of SA research by showing that NF can be a useful instrument for exploring SA as a holistic experience encompassing both language-related and non-language-related aspects. This study has shown that NFs yield exciting results when used alone, but their potential may be even more pronounced when used in conjunction with other instruments (e.g. interviews or questionnaires), which future studies might explore. The known potential limitations of the NFs remain: the incompatibility 
between researcher's vision and participant's perception of the story structure, limited possibilities to include other (non-framed) topics, discrepancies between researcher's and participant's interpretations of the prompts and the narrative. We hope to have mitigated these by trialling our NF, administering it in electronic form, and involving two authors in the analysis.

[Paper submitted 3 Sep 2019]

[Revised version received 16 Oct 2019]

[Revised version accepted for publication 20 Oct 2019]

\section{References}

Ayano, M. (2006). Japanese students in Britain. In M. Byram, \& A. Feng (Eds.), Living and studying abroad: Research and practice (pp. 11-37). Clevedon: Multilingual Matters.

Bagić, T., \& Vrhovac, Y. (2012). Developing intercultural competence of Croatian high school students on a study abroad by means of ethnographic research tasks. Croatian Journal of Education, 14(2), 417-436.

Barkhuizen, G. (2014). Revisiting narrative frames: An instrument for investigating language teaching and learning. System, 47, 12-27.

Benson, P., Barkhuizen, G., Bodycott, P., \& Brown, J. (2013). Second language identity in narratives of study abroad. London: Palgrave MacMillan.

Brecht, R. D., \& Robinson, J. (1993). Qualitative analysis of second language acquisition in study abroad: The ACTR/NFLC project. Washington, DC: National Foreign Language Center.

Brecht, R., \& Robinson, J. (1995). On the value of formal instruction in study abroad: Student reactions in context. In B. F. Freed (Ed.), Second language acquisition in a study abroad context (pp. 317-334). Amsterdam: John Benjamins.

Charmaz, K. (2006). Constructing grounded theory: A practical guide through qualitative analysis. London: Sage Publications.

Cheng, L., \& Fox, J. (2008). Towards a better understanding of academic acculturation: Second language students in Canadian universities. The Canadian Modern Language Review, 65(2), 307-333.

Freed, B. (1998). An overview of issues and research in language learning in a study abroad setting. Frontiers: The Interdisciplinary Journal of Study Abroad, 4(2), 31-60.

Guvendir, E. (2017). Turkish students and their experiences during a short-term summer visit to the U.S. Study Abroad Research in Second Language Acquisition and International Education, 2(1), 21-52.

Isabelli, C. A. (2007). Development of the Spanish subjunctive by advanced learners: Study abroad followed by at-home instruction. Foreign Language Annals, 40, 330-341.

Isabelli-García, C., Bown, J., Plews, J. L., \& Dewey, D. P. (2018). Language learning and study abroad. Language Teaching, 51(4), 439-484.

Jackson, J. (2006). Ethnographic pedagogy and evaluation in short-term study abroad. In M. Byram, \& A. Feng (Eds.), Living and studying abroad: Research and practice (pp. 132-185). Clevedon: Multilingual Matters. 
Kimura, D. (2019). "Seriously, I came here to study English": A narrative case study of a Japanese exchange student in Thailand. Study Abroad Research in Second Language Acquisition and International Education, 4(1), 70-95.

Kinginger, C. (2008). Language learning in study abroad: Case studies of Americans in France. The Modern Language Journal, 92, 1-124.

Kinginger, C. (2009). Language learning and study abroad: A critical reading of research. New York: Palgrave Macmillan.

Llanes, À., Arnó, E., \& Mancho-Barés, G. (2016). Erasmus students using English as a lingua franca: Does study abroad in a non-English-speaking country improve L2 English? The Language Learning Journal, 44(3), 292-303.

Miller, L., \& Ginsberg, R. B. (1995). Folklinguistic theories of language learning. In B. F. Freed (Ed.), Second language acquisition in a study abroad context (pp. 293-315). Amsterdam: John Benjamins.

Oxford, R. (2017). Teaching and researching language learning strategies: Self-regulation in context. New York: Routledge.

Pearson-Evans, A. (2006). Recording the journey: Diaries of Irish students in Japan. In M. Byram, \& A. Feng (Eds.), Living and studying abroad: Research and practice (pp. 3863). Clevedon: Multilingual Matters.

Pellegrino, V. (1998). Student perspectives on language learning in a study abroad context. Frontiers: The Interdisciplinary Journal of Study Abroad, 4(2), 91-120.

Pidgeon, N. (1996). Grounded theory: Theoretical background. In J. T. E. Richardson (Ed.), Handbook of qualitative research methods for psychology and the social sciences (pp. 75-85). Leicester: BPS Books.

Riedel, K. G. (1989). New goals for teaching language: An experience in undergraduate programs in Spain. Hispania, 72, 774-779.

Schumann, F., \& Schumann, J. (1977). Diary of a language learner: An introspective study of SLA. In H. Brown, C. Yorio, \& R. Crymes (Eds.), On TESOL '77 (pp. 241-249). Washington, DC: TESOL.

Slagter, C., \& Pyper, M. (2019). Linguistic loneliness and study abroad. Frontiers: The Interdisciplinary Journal of Study Abroad, 21(1), 46-58.

Strauss, A., \& Corbin, J. (1998). Grounded theory methodology. In N. K. Denzin, \& Y. S. Lincoln (Eds.), Strategies of qualitative inquiry (pp. 158-183). Thousand Oaks: Sage Publications.

Strauss, A., \& Corbin, J. M. (1990). Basics of qualitative research: Grounded theory procedures and techniques. Thousand Oaks: Sage Publications.

Swales, J. M. (1990). Genre analysis: English in academic and research settings. Cambridge: Cambridge University Press.

Swenson, T., \& Visgatis, B. (2011). Narrative frames to assess overseas experiences. In A. Stewart (Ed.), JALT2010 conference proceedings (pp. 441-452). Tokyo: JALT.

Taylor, D. (1994). Inauthentic authenticity or authentic inauthenticity? TESL-EJ, 1(2). Retrieved from http://www.tesl-ej.org/wordpress/issues/volume1/ej02/ej02a1/

Vollstedt, M., \& Rezat, S. (2019). An introduction to grounded theory with a special focus on axial coding and the coding paradigm. In G. Kaiser, \& N. Presmeg (Eds.), Compendium for early career researchers in mathematics education. ICME-13 monographs (pp. 81-100). Cham: Springer.

Wang, C. (2010). Toward a second language socialization perspective: Issues in study abroad research. Foreign Language Annals, 43(1), 50-63. 
Widdowson, H. G. (1998). Context, community, and authentic language. TESOL Quarterly, 32(4), 705-716.

Wilkinson, S. (1998). Study abroad from the participants' perspective: A challenge to common beliefs. Foreign Language Annals, 31(1), 23-39.

Yang, J. (2016). The effectiveness of study-abroad on second language learning: A metaanalysis. The Canadian Modern Language Review, 72(1), 66-94.

Zlomislić, J., Gverijeri, LJ. R., \& Bugarić, E. (2016). The significance of intercultural competence in cross-cultural communication. Ekonomski vjesnik, 29(2), 433-451.

SANJA MARINOV is a PhD candidate at the Faculty of Humanities and Social Sciences in Zagreb, Croatia. She is a lecturer in languages for specific purposes at the Faculty of Economics, Business and Tourism in Split, Croatia. Her professional and scientific interests include designing study materials for English in tourism, data-driven learning, vocabulary learning strategies, lexical competence, and lexical development during study abroad.

VIŠNJA PAVIČIĆ TAKAČ is a Full Professor at the Faculty of Humanities and Social Sciences in Osijek, Croatia. Her research interests include individual differences in FL learning, language learning strategies, communicative competence, lexical development, cross-linguistic studies, and pre-service teacher education. She has participated in several scientific projects and presented over forty papers at conferences. She authored and co-authored three books and four edited volumes, and over fifty published papers and book chapters. 


\section{Appendix 1 Example of a completed and coded NF}

This is a story about my study abroad experience. I decided to apply for study abroad because I knew this was the best possible opportunity for personal growth and development in every possible way [GOAL_NL_person_develop].

Before my study abroad period English I spoke was on an intermediate, I'd say B2 level [PRESA_ELP_int], and I think this is because I had no opportunity to use it on daily basis [ATT_PRESA_ELP_int_lack_regularuse]. The most difficult way of learning English was 0, while the easiest way was 0 . It is because 0. In English, I was good at speaking [PRESA_STRP_speaking], and the biggest problem was writing [PRESA_WEAKP_writing]. When I had to express myself in writing I always had to use various translation tools because I was not sure how to write particular words [PRESA_LS_internet].

During the study abroad period I used English on daily basis [SAUSE_daily]. That was great because that is the only way to improve your language skills [SAUSE_PERC_constexpo_useful_BLL]. It was easy to use English when speaking to other students [SAUSE_EASY_otherst] in everyday informal situations [SAUSE_EASY_informal], and it was difficult to use English in lectures at the university [SAUSE_DIFF_formal]. It is because my level of business English was not sufficient [ATT_SAUSE_DIFF_formal_lack_LSP]. We have more opportunities to hear informal English by watching films and listening to music [AT__SAUSE_EASY_informal_constexpo] while this is not the case with business English [AT__SAUSE_DIFF_formal_lack_constexpo_LSP]. As for the classes 0.

I preferred to communicate with other Erasmus students [IP_otherES]. I particularly liked talking to native speakers of English [IP_NS] and other students who study in English even in their home institutions [IP_proficient_users] because this is the best way to improve your language and enrich your vocabulary [ATT_IP_NS_languagesource] [ATT_IP_proficient_users_languagesource]. I avoided communication 0 because 0 .

The English used/spoken by my interlocutors was most often worse than mine [ELP_INTERLOC_lower]. At my Erasmus I was often in the company of Spanish and Portuguese students and their English proficiency is somewhat lower than ours. I think that Croatian students are quite good at English. This 0 . In a conversation when I didn't fully understand my interlocutors I would ask them to repeat [CS_askrepeat] or explain in some other way what they wanted to say [CS_paraph]. This was not often the case because I understood English very well.

If I didn't understand something while reading in English I used Google translate [LS_internet]. On the other hand, when I was not sure how to say or write something I also used Google translate [CS_LS_internet].

During my study abroad period I studied English through speaking at the university [SALL_formal] and hanging out with the colleagues [SALL_informal]. I also 0.

After study abroad my English has greatly improved [POSTSA_L_impr]. I am also more relaxed [POSTSA_ACH_lower_lang_anx] and more self-confident [POSTSA_ACH_high_confidence] and, therefore, I now have no problem to speak English at any time. There is simply no anxiety anymore and I feel more open to speaking. I think it is because I had to use it on daily basis [ATT_POSTSA_lower_lang_anx_regularuse] [ATT_POSTSA_high_confidence_regularuse] since there were no Croats around. I made progress in 0 , and I didn't make progress in 0 . It is because 0 .

What I learnt from this experience is that we learn languages best when abroad and when we have no other choice but to use it regularly [SAEXP_importance_of_immersion] so I believe that in the future I will travel more to improve foreign languages [CONC_traveltolearnlanguages]. If I could repeat the study abroad experience I would certainly do it [IF_AGAIN_yes_bestexperience] and I would encourage all students to use this opportunity while they still can. Otherwise they will be sorry for the opportunity not taken. This is certainly one of the best experiences that I will remember it for the rest of my life. 


\section{Appendix 2}

\section{Demographic questionnaire}

\begin{tabular}{|c|c|}
\hline $\begin{array}{l}1 \text { What is the name of your home } \\
\text { institution and what is your course } \\
\text { of study? }\end{array}$ & \\
\hline $\begin{array}{l}2 \text { In which semester did you } \\
\text { accomplish your study abroad? }\end{array}$ & \\
\hline $\begin{array}{l}3 \text { What is the name of your host } \\
\text { institution and city? }\end{array}$ & \\
\hline 4 How long did you study abroad? & \\
\hline $\begin{array}{l}5 \text { Did you attend classes at your host } \\
\text { institution and in what language? }\end{array}$ & \\
\hline $\begin{array}{l}6 \text { Do you speak the language of the } \\
\text { host country? }\end{array}$ & \\
\hline $\begin{array}{l}7 \text { How much contact with Croatian } \\
\text { did you have? Please explain. }\end{array}$ & \\
\hline
\end{tabular}

